\title{
Práticas curriculares e de avaliação da aprendizagem: contributos para a melhoria
}

Ivone Sá

Agrupamento de Escolas Pintor José de Brito, Viana do Castelo

Portugal

Fátima Sousa-Pereira Escola Superior de Educação - Instituto Politécnico de Viana do Castelo; Centro de Investigação e Intervenção Educativas (CIIE) Faculdade de Psicologia e de Ciências da Educação da Universidade do Porto - Portugal

\section{Resumo}

Neste artigo apresenta-se um estudo impulsionado pelo Programa Nacional de Promoção do Sucesso Escolar e pelos resultados da Avaliação Externa das Escolas, que pretendeu identificar práticas curriculares e de avaliação da aprendizagem nas disciplinas de matemática, ciências naturais e físico-química num agrupamento de escolas do norte de Portugal. Para o efeito, recorreu-se a um questionário para a coleta de dados junto de professores $(n=14)$ e estudantes do $3^{\circ}$ ciclo do ensino básico $(n=238)$. Os resultados evidenciam a necessidade de mudanças nas práticas pedagógicas e didáticas consentâneas com um paradigma formativo centrado na aprendizagem que promova o envolvimento ativo dos estudantes nesse processo.

Palavras-chave: Práticas Curriculares. Avaliação da Aprendizagem. Melhoria Educacional. Sucesso Educativo.

\section{Prácticas curriculares y de evaluación del aprendizaje: contribuciones a la mejora}

\section{Resumen}

En este artículo se presenta un estudio que tuvo como punto de partida el Programa Nacional de Promoción del Éxito Escolar y la Evaluación Externa de las Escuelas, que pretendió identificar prácticas curriculares y de evaluación del aprendizaje en las disciplinas de matemáticas, ciencias naturales y físico-química en una agrupación de 
escuelas del norte de Portugal. Para ello, se recurrió a un cuestionario para la recogida de datos entre profesores $(n=14)$ y estudiantes del $3^{\circ}$ ciclo de enseñanza básica $(n=$ 238). Los resultados evidencian la necesidad de cambios en las prácticas pedagógicas y didácticas acordes con un paradigma formativo centrado en el aprendizaje que promueve la participación activa de los estudiantes en ese proceso.

Palabras clave: Prácticas Curriculares. Evaluación del Aprendizaje. Mejora Educativa. Éxito Educativo.

\title{
Curricular practices and learning assessment: contribu- tions to improvement
}

\begin{abstract}
This paper presents a study which took as its starting point the National Program for the Promotion of School Success and the External Evaluation of Schools, which aimed to identify curricular practices and learning assessment practices in mathematics, natural sciences and physicochemistry in a grouping of schools in the north of Portugal. For this purpose, a questionnaire was used to collect data from teachers $(n=14)$ and students from the 3rd cycle of basic education $(n=238)$. The results show the need for changes in educational and teaching practices in line with an educational paradigm focused on learning that support the active involvement of students in the process.
\end{abstract}

Keywords: Curricular Practices. Learning Assessment. Educational Improvement. Educational Success.

\section{Pratiques curriculaires et d'évaluation des apprentissa- ges: contributions à l'amélioration}

\section{Résumé}

Dans cet article, une étude est présentée à partir de la National pour la Promotion de la Réussite Scolaire et de la Évaluation Externe des Écoles, qui visait à identifier les pratiques curriculaires et d'évaluation des apprentissages en mathématiques, en sciences naturelles et en physicochimie dans un groupe de écoles du nord du Portugal. À cette fin, un questionnaire a été utilisé pour la collecte de données auprès des 
enseignants ( $n=14)$ et des élèves du troisième cycle de l'éducation de base ( $n=238$ ). Les résultats montrent la nécessité de changements dans les pratiques éducatives et d'enseignement en ligne avec un paradigme éducatif axé sur l'apprentissage pour soutenir la participation active des élèves dans le processus.

Mots-clés: Pratiques Curriculaires. Évaluation de l'apprentissage. Amélioration de l'éducation. Succès Éducatif.

\section{Introdução}

As últimas décadas do século $X X$ e este início de século têm vindo a colocar grandes e constantes desafios aos sistemas educativos em resultado do ritmo de desenvolvimento do conhecimento científico e tecnológico. A esses desafios, relacionados com o ritmo da produção e disseminação do conhecimento e das modalidades de acesso ao mesmo, acrescem outros que se prendem, em particular, com a promoção do sucesso educativo. Efetivamente, as mudanças associadas à massificação do acesso à educação e ao alargamento da escolaridade obrigatória acarretaram para o sistema educativo preocupações acrescidas com a garantia do sucesso, com repercussões nas expetativas sociais face à escola, no alargamento do perfil de desempenho docente e na complexidade do trabalho daí resultante.

Gerir uma escola, assim como gerir o processo de ensino-aprendizagem e de avaliação, apresenta-se, portanto, como algo extremamente complexo, exigindo o aperfeiçoamento das práticas pedagógicas para a melhoria da qualidade do ensino e da aprendizagem (Amorim \& Alves, 2015; Bolívar, 2012; Lima, 2008), assim como a criação de condições organizacionais que sustentem estas mudanças curriculares no núcleo da ação educativa (Hopkins, 2001).

Embora, de acordo com resultados recentes da OCDE (Moreira, 2014), Portugal tenha sido o país que mais progrediu no que diz respeito aos níveis de escolarização, também é um fato que os níveis de sucesso ainda se situam aquém do desejável. Para responder a este problema, têm sido várias as medidas políticas implementadas na tentativa de elevar os níveis de qualidade na educação. Na última década, é de destacar, a título de exemplo, o Programa Mais Sucesso Escolar (PMSE), em 2009, e o Programa Nacional de Promoção do Sucesso Escolar (PNPSE), em 2016, ambos comprometidos com a mudança de práticas curriculares docentes e com o sucesso educativo para todos.

É no quadro desta problemática que se situa a pesquisa que neste artigo se apresenta sobre práticas curriculares e de avaliação da aprendizagem num agrupamento de escolas do norte de Portugal. Para o efeito, partiu-se de um referencial teórico que sustenta a necessidade de mudanças nas escolas com impacto positivo no núcleo da ação educativa, reconhecendo-se que a melhoria da qualidade dos contextos educativos terá que passar pela ruptura com abordagens curriculares mais tradicionais 
e tecnicistas (Leite, 2002, 2003; Pacheco, 2001), criando oportunidades para o envolvimento ativo dos estudantes na construção de aprendizagens significativas. 0 estudo questionou professores, e respetivos alunos, das disciplinas de matemática, ciências naturais e físico-química, quanto a práticas curriculares docentes mais utilizadas, mais apreciadas pelos estudantes e promotoras de mais e melhores aprendizagens.

\section{Da complexidade dos processos de mudança e inovação educacional}

Não obstante o reconhecimento generalizado da necessidade de mudança e inovação educacional, e apesar da pressão exercida pelas políticas neste domínio, a transformação dos sistemas educativos tem-se revelado um processo lento e, em geral, a escola continua a espelhar um modelo organizacional e curricular muito tradicionalista.

Esta tendência para a estabilidade e permanência das práticas organizacionais e curriculares tem convivido em Portugal, desde a década de 80 do século XX e de forma ainda mais acentuada nesta última década, com a crescente legislação educativa que aponta para determinados perfis de mudança, relacionados nomeadamente com a criação de condições para o sucesso educativo. A título de exemplo, e além dos dois programas já referidos (PMSE e PNPSE), destacam-se o Programa Interministerial de Promoção do Sucesso Educativo (PIPSE), o Programa Educação para Todos (PEPT), os Territórios Educativos de Intervenção Prioritária (TEIP), «Eu não desisto» - Plano Nacional de Prevenção do Abandono Escolar (PNAPAE), PIEF - Plano Integrado de Educação e Formação, CEF - Cursos de Educação e Formação, entre outros.

Mas, como argumentam vários autores (Campos, 2002; Canário, 1996; Bolívar, 2012; Fullan \& Hargreaves, 2001; Hargreaves, 1998; Leite, 2003; Nóvoa, 2009; Thurler, 1994; Whitaker, 1999), as práticas educativas não se mudam por decreto, tendendo a ser fruto dos próprios profissionais e não tanto da regulamentação. Além disso, muitas medidas políticas orientadas para a produção de mudança nos contextos educativos acabam por resultar em situações de perturbação cognitiva permanente nas escolas e nos professores, podendo inclusivamente ter contribuído para a crise de identidade vivida pelos professores na atualidade (Crozier, 1995; Fullan, 1993; Schön, 1992).

Fullan $(1993,1999,2003)$ chama precisamente a atenção para a multiplicidade de forças que intervêm nos processos de mudança e para o número de variáveis envolvidas e respectivas interações possíveis. Este autor argumenta que o fracasso de muitas reformas educativas deve-se principalmente a duas grandes razões: uma relacionada com a complexidade dos problemas que estão na base das reformas e que remetem, pela sua natureza, para soluções também elas complexas; a segunda relacionada com as estratégias desenvolvidas e que na maioria dos casos não se focam em aspectos de primeira ordem, ou seja, naquilo que realmente pode fazer a 
diferença (Fullan,1993).

No entanto, apesar do insucesso associado a muitas destas propostas legislativas, não desapareceu a ideia de empreender a mudança, cada vez mais sentida como um imperativo das sociedades tecnologicamente avançadas. Aceitando que as escolas são organizações que aprendem, o esforço de melhoria deve refletir adaptações de práticas que transformem o processo de aprendizagem para alcançar o máximo impacto sobre estudantes, professores e escolas (Hopkins, 2001; Bolívar, 2012).

Admite-se que neste processo há que atender à capacidade dos órgãos de gestão de uma escola para envolver a comunidade educativa, nomeadamente em práticas de autoavaliação organizacional que potenciem a melhoria. Ainscow, Beresford, Harris, Hopkins e West (2001) referem que "la mejora de la escuela funciona de manera óptima cuando se establece un objectivo de innovación, claro y práctico, que está ligado ao trabajo simultáneo sobre las condiciones internas de la escuela", o que resultará facilitado se se desenvolverem mecanismos de liderança centrados na aprendizagem e no sucesso educativo, comprometidos com o desenvolvimento de cada escola como comunidade de aprendizagem profissional (Bolívar; 2012).

O Programa Nacional de Promoção do Sucesso Escolar (PNPSE), criado através da Resolução do Conselho de Ministros n 23/2016, tem como grande objetivo promover um ensino de qualidade para todos, num quadro de valorização da igualdade de oportunidades e do aumento da eficiência e qualidade das escolas. Neste sentido, tem como orientação de base a ideia de que são "as comunidades educativas quem melhor conhece os seus contextos, as dificuldades e potencialidades, sendo, por isso, quem está melhor preparado para encontrar soluções locais e conceber planos de ação estratégica, pensados ao nível de cada escola, com o objetivo de melhorar as práticas educativas e as aprendizagens dos alunos." (Resolução do Conselho de Ministros nº 23/2016, Preâmbulo).

Não obstante a pertinência desta medida, as metas estabelecidas são muito ambiciosas e difíceis de cumprir, nomeadamente no âmbito das disciplinas em análise no estudo desenvolvido. No entanto, reconhecendo-se que as escolas existem para que os alunos aprendam e que é ao nível das práticas curriculares docentes que se pode fazer a diferença no que diz respeito ao sucesso escolar, desenvolveu-se um estudo focado nesta dimensão com o intuito de obter um diagnóstico organizacional que permita a melhoria de processos e resultados. Neste estudo, e corroborando as perspetivas de Bolívar (2012) e Hopkins (2007), partiu-se da ideia de que os dados sobre a aprendizagem dos alunos (sejam eles relativos a processos ou resultados, sejam eles resultantes de um diagnóstico interno ou da avaliação externa das escolas) devem constituir uma base fundamental para a planificação de processos de mudança e melhoria educacional.

\section{Enquadramento do estudo empírico e aspectos metodológicos}


Tendo por base este enquadramento, o estudo desenvolvido pretendeu identificar práticas curriculares nas disciplinas de matemática, ciências naturais e físico-química num agrupamento de escolas do norte de Portugal.

Sem perder de vista a grande finalidade do PNPSE, ou seja, de promover um ensino de qualidade para todos, o agrupamento de escolas no âmbito do qual se desenvolveu o estudo elegeu as três disciplinas referidas como disciplinas alvo de intervenção no $3^{\circ}$ ciclo do ensino básico, dada a grande percentagem de alunos transitados com nível inferior a três (ou seja, com nível inferior a suficiente).

Participaram do estudo 238 alunos dos $7^{\circ}, 8^{\circ}$ e $9^{\circ}$ ano de escolaridade e os respectivos professores que lecionam as disciplinas de matemática, ciências naturais e físico-química, num total de 14 professores.

Para a coleta de dados, foi utilizado um questionário sobre práticas curriculares docentes (ensino-aprendizagem e avaliação), da autoria de Leite, Fernandes e SousaPereira (2018), que foi adaptado, no âmbito deste estudo, para a recolha de dados junto de professores e alunos. Ambos os participantes foram questionados sobre práticas de ensino-aprendizagem e os professores foram também inquiridos sobre práticas de avaliação da aprendizagem. No entanto, com o objetivo de no processo de análise e interpretação dos dados se poder triangular as perspectivas destes dois tipos de participantes relativamente às práticas curriculares, os questionários assumiram uma estrutura semelhante, sendo de registrar apenas alguns ajustes em função do papel desempenhado por cada participante no processo educativo.

Com efeito, o questionário dos alunos foi estruturado em dois blocos: o primeiro direcionado para a coleta de dados pessoais e o segundo para recolha de dados sobre práticas curriculares (ensino-aprendizagem) mais usadas pelos docentes, práticas mais apreciadas pelos estudantes e práticas que se considera proporcionarem mais e melhores aprendizagens (nas três disciplinas em análise).

O questionário dos professores foi estruturado em três blocos: o primeiro direcionado para a recolha de dados pessoais; o segundo para coleta de dados sobre práticas curriculares (ensino-aprendizagem) mais usadas pelos docentes, práticas mais apreciadas pelos estudantes e práticas que se considera proporcionarem mais e melhores aprendizagens; e o terceiro bloco orientado para a recolha de informação sobre práticas avaliativas (instrumentos/procedimentos de avaliação da aprendizagem) mais utilizadas pelos docentes, práticas avaliativas mais apreciadas pelos estudantes e práticas avaliativas que se considera promoverem mais e melhores aprendizagens.

No que diz respeito a práticas de ensino-aprendizagem, os questionários dispunham de 21 itens, podendo ser escolhidas, no máximo, dez práticas curriculares, numeradas de acordo com o grau de importância atribuída ou frequência com que são utilizadas. Relativamente às práticas de avaliação da aprendizagem, os questionários dispunham de 12 itens, podendo ser escolhidas, no máximo, sete práticas curriculares, numeradas 
de acordo com o mesmo critério.

Os dados recolhidos, de natureza quantitativa, foram submetidos à análise estatística.

\section{Apresentação de resultados}

Inicia-se a apresentação dos resultados pela informação relativa às respostas dos alunos, seguindo-se os dados dos professores.

\section{A perspectiva dos estudantes sobre as práticas curriculares docentes}

Uma caracterização dos alunos mostra que 55,9\% $(n=133)$ dos estudantes que participaram do estudo são do sexo masculino e 44,1\% ( $n=105)$ são do sexo feminino. Relativamente ao ano de escolaridade, 35,3\% (n=84) são alunos do $8^{\circ}$ ano, 33,2\% $(n=79)$ do $9^{\circ}$ ano e $31,5 \%(n=75)$ do $7^{\circ}$ ano de escolaridade.

Quando questionados sobre as práticas curriculares que os docentes de matemática, físico-química e ciências naturais mais utilizam nas aulas, constata-se que na disciplina de matemática se destaca a exposição/explicação dos conteúdos seguida de exercícios para aplicação/consolidação dos conhecimentos $(n=216)$. É ainda referida: a abordagem aos conteúdos seguindo predominantemente a estrutura dos manuais $(n=185)$, a exposição/explicação dos conteúdos $(n=157)$ e a exposição/explicação dialogada dos conteúdos com os alunos $(n=154)$. Numa situação intermédia do número de respostas, é feita referência à apresentação de dados ou exemplos para análise pelos alunos seguida de apresentação e explicação dos conceitos em estudo $(n=106)$ e a realização de atividades de sistematização e de relação de conhecimentos (gráficos, esquemas, diagramas, mapas conceituais etc.) $(n=101)$. As práticas que os alunos mencionam ser utilizadas com menos frequência pelos docentes de matemática são a realização de trabalhos de campo e visitas de estudo $(n=14)$, assim como a participação em iniciativas de caráter científico, nomeadamente trabalho experimental e projetos de investigação $(n=7)$.

Relativamente às práticas usadas mais regularmente pelos docentes de físicoquímica, constata-se o predomínio da exposição/explicação dos conteúdos ( $n=171)$, seguindo-se a exposição/explicação dialogada dos conteúdos com os alunos $(n=170)$, a exposição/explicação dos conteúdos seguida de exercícios para aplicação/consolidação dos conhecimentos $(n=167)$ e a realização de trabalhos de grupo $(n=160)$. Numa posição intermédia do número de referências, surgem a abordagem aos conteúdos seguindo predominantemente a estrutura dos manuais $(n=139)$ e a apresentação de dados ou exemplos para análise pelos alunos seguida de apresentação e explicação dos conceitos em estudo ( $n=126)$. As práticas menos utilizadas pelos professores que lecionam físico-química, segundo a visão dos alunos 
inquiridos, são a realização de atividades promotoras de criatividade (criar uma nova visão, uma nova solução, um novo cenário, planejar, imaginar, construir, entre outras) $(n=23)$, a realização de atividades de análise de textos e/ou de outros recursos $(n=24)$ e a promoção de debates através de fóruns virtuais $(n=26)$.

Quando questionados sobre as práticas curriculares adotadas mais frequentemente pelos docentes de ciências naturais, das respostas dos alunos destacam-se igualmente a exposição/explicação dos conteúdos $(n=169)$ e a exposição/explicação dialogada dos conteúdos com os alunos $(n=157)$, seguida da realização de trabalho de grupo $(n=151)$. É de registrar também a adoção regular da exposição/explicação dos conteúdos seguida de exercícios para aplicação/consolidação dos conhecimentos ( $n=131)$ e a apresentação de dados ou exemplos para análise pelos alunos seguida de apresentação e explicação dos conceitos em estudo $(n=124)$. A realização de atividades que têm em conta as caraterísticas da turma (conhecimentos prévios; experiências de vida) ( $n=114)$ e a abordagem aos conteúdos seguindo predominantemente a estrutura dos manuais ( $n=112$ ) são igualmente práticas referidas por um número significativo de alunos. Por outro lado, a realização de atividades promotoras de criatividade (criar uma nova visão, uma nova solução, um novo cenário, planear, imaginar, construir, entre outros) ( $n=28$ ) não é referida como uma prática frequente, tal como acontece com a análise de casos relativos a situações diversas que contribuam para o desenvolvimento de competências de pensamento crítico e para a resolução de problemas $(n=32)$ e com o recurso a atividades que permitam transformar as experiências reais dos alunos em assuntos de aprendizagem $(n=36)$. A tabela 1 sistematiza as respostas dos alunos inquiridos a esta pergunta.

Tabela 1: Práticas curriculares docentes usadas com mais frequência - perspectiva dos estudantes

\begin{tabular}{|l|r|r|r|r|r|r|}
\hline \multirow{2}{*}{$\begin{array}{l}\text { Práticas curriculares do- } \\
\text { centes } \\
\text { (ensino-aprendizagem) }\end{array}$} & \multicolumn{2}{|c|}{ Matemática } & \multicolumn{2}{|c|}{$\begin{array}{c}\text { Físico-Quí- } \\
\text { mica }\end{array}$} & $\begin{array}{c}\text { Ciências Na- } \\
\text { turais }\end{array}$ \\
\cline { 2 - 8 } & $\mathbf{n}^{\circ}$ & Média & no & $\begin{array}{r}\text { Mé- } \\
\text { dia }\end{array}$ & $\mathbf{n}^{\mathbf{0}}$ & Média \\
\hline $\begin{array}{l}\text { Exposição/Explicação dos conte- } \\
\text { údos }\end{array}$ & 157 & 2,5 & 171 & 1,8 & 169 & 1,7 \\
\hline $\begin{array}{l}\text { Exposição/Explicação dialogada } \\
\text { dos conteúdos com os alunos }\end{array}$ & 154 & 2,8 & 170 & 2,0 & 157 & 2,2 \\
\hline $\begin{array}{l}\text { Exposição/Explicação dos conte- } \\
\text { údos seguida de exercícios para } \\
\text { aplicação/consolidação dos co- } \\
\text { nhecimentos }\end{array}$ & 216 & 1,9 & 167 & 3,1 & 131 & 3,1 \\
\hline
\end{tabular}




\begin{tabular}{|c|c|c|c|c|c|c|}
\hline \multirow{2}{*}{$\begin{array}{l}\text { Práticas curriculares do- } \\
\text { centes } \\
\text { (ensino-aprendizagem) }\end{array}$} & \multicolumn{2}{|c|}{ Matemática } & \multicolumn{2}{|c|}{$\begin{array}{l}\text { Físico-Quí- } \\
\text { mica }\end{array}$} & \multicolumn{2}{|c|}{$\begin{array}{c}\text { Ciências } \mathrm{Na}- \\
\text { turais }\end{array}$} \\
\hline & $n^{0}$ & Média & $n^{0}$ & $\begin{array}{l}\text { Mé- } \\
\text { dia }\end{array}$ & $n^{0}$ & Média \\
\hline $\begin{array}{l}\text { Apresentação de dados ou exem- } \\
\text { plos para análise pelos alunos se- } \\
\text { guida de apresentação e explica- } \\
\text { ção dos conceitos em estudo }\end{array}$ & 106 & 4,2 & 126 & 3,9 & 124 & 3,5 \\
\hline $\begin{array}{l}\text { Realização de atividades que têm } \\
\text { em conta as caraterísticas da tur- } \\
\text { ma (conhecimentos prévios; ex- } \\
\text { periências de vida...) }\end{array}$ & 77 & 5,1 & 91 & 4,3 & 114 & 4,1 \\
\hline $\begin{array}{l}\text { Abordagem aos conteúdos se- } \\
\text { guindo, predominantemente, a } \\
\text { estrutura dos manuais }\end{array}$ & 185 & 2,7 & 139 & 5,1 & 112 & 4,1 \\
\hline $\begin{array}{l}\text { Realização de atividades de pes- } \\
\text { quisa bibliográfica ou de pesquisa } \\
\text { através de trabalho de campo }\end{array}$ & 23 & 6,3 & 59 & 5,8 & 66 & 5,4 \\
\hline $\begin{array}{l}\text { Realização de trabalhos de cam- } \\
\text { po e de visitas de estudo }\end{array}$ & 14 & 7,1 & 89 & 7,1 & 85 & 5,3 \\
\hline $\begin{array}{l}\text { Recurso a atividades que permi- } \\
\text { tam transformar as experiências } \\
\text { reais dos alunos em assuntos de } \\
\text { aprendizagem }\end{array}$ & 43 & 5,8 & 68 & 5,4 & 36 & 6,5 \\
\hline Realização de trabalho de grupo & 35 & 5,8 & 160 & 5,6 & 151 & 3,5 \\
\hline $\begin{array}{l}\text { Realização de atividades de aná- } \\
\text { lise de textos e/ou de outros re- } \\
\text { cursos }\end{array}$ & 50 & 5,8 & 24 & 6,1 & 61 & 5,6 \\
\hline $\begin{array}{l}\text { Promoção de situações de diálo- } \\
\text { go e de partilha de saberes entre } \\
\text { os alunos }\end{array}$ & 81 & 5,1 & 66 & 5,9 & 79 & 6,2 \\
\hline $\begin{array}{l}\text { Promoção de debates através de } \\
\text { fóruns virtuais }\end{array}$ & 30 & 5,5 & 26 & 5,6 & 47 & 4,3 \\
\hline $\begin{array}{l}\text { Promoção de dinâmicas de deba- } \\
\text { te e confronto de opiniões numa } \\
\text { lógica argumentativa entre os } \\
\text { alunos }\end{array}$ & 48 & 6,4 & 33 & 6,2 & 49 & 6,0 \\
\hline $\begin{array}{l}\text { Realização de atividades de análi- } \\
\text { se e reflexão de situações do dia- } \\
\text {-a-dia e do mundo }\end{array}$ & 31 & 6,3 & 64 & 5,7 & 51 & 6,0 \\
\hline
\end{tabular}




\begin{tabular}{|c|c|c|c|c|c|c|}
\hline \multirow{2}{*}{$\begin{array}{l}\text { Práticas curriculares do- } \\
\text { centes } \\
\text { (ensino-aprendizagem) }\end{array}$} & \multicolumn{2}{|c|}{ Matemática } & \multicolumn{2}{|c|}{$\begin{array}{l}\text { Físico-Quí- } \\
\text { mica }\end{array}$} & \multicolumn{2}{|c|}{\begin{tabular}{|c|} 
Ciências $\mathrm{Na}-$ \\
turais
\end{tabular}} \\
\hline & $n^{0}$ & Média & $n^{0}$ & $\begin{array}{r}\text { Mé- } \\
\text { dia }\end{array}$ & $\mathrm{n}^{0}$ & Média \\
\hline $\begin{array}{l}\text { Promoção de situações de entre- } \\
\text { ajuda entre alunos }\end{array}$ & 72 & 5,9 & 50 & 5,6 & 37 & 6,4 \\
\hline $\begin{array}{l}\text { Conceção e desenvolvimento de } \\
\text { trabalhos de projeto }\end{array}$ & 20 & 5,1 & 74 & 6,5 & 39 & 6,6 \\
\hline $\begin{array}{l}\text { Participação em iniciativas de ca- } \\
\text { ráter científico, nomeadamente } \\
\text { trabalho experimental e projetos } \\
\text { de investigação }\end{array}$ & 7 & 6,0 & 128 & 6,0 & 50 & 6,5 \\
\hline $\begin{array}{l}\text { Análise de casos relativos a situ- } \\
\text { ações diversas que contribuam } \\
\text { para o desenvolvimento de com- } \\
\text { petências de pensamento crítico } \\
\text { e para a resolução de problemas }\end{array}$ & 53 & 6,2 & 54 & 7,1 & 32 & 6,8 \\
\hline $\begin{array}{l}\text { Realização de atividades de sis- } \\
\text { tematização e de relação de co- } \\
\text { nhecimentos (gráficos, esquemas, } \\
\text { diagramas, mapas concetuais, ...) }\end{array}$ & 101 & 4,9 & 55 & 6,9 & 57 & 6,2 \\
\hline $\begin{array}{l}\text { Realização de atividades promo- } \\
\text { toras de criatividade (criar uma } \\
\text { nova visão, uma nova solução, um } \\
\text { novo cenário, planear, imaginar, } \\
\text { construir, ...) }\end{array}$ & 41 & 6,7 & 23 & 6,7 & 28 & 6,1 \\
\hline Outra (s) & 53 & 8,0 & 23 & 7,2 & 24 & 6,1 \\
\hline
\end{tabular}

Fonte: Dados resultantes do estudo

Num segundo momento, tendo sido solicitado aos estudantes para indicarem as práticas curriculares que, em geral, mais apreciam enquanto alunos, verifica-se (Tabela 2) que se destacam duas práticas em particular: realização de trabalhos de grupo ( $n=199)$ e a realização de trabalhos de campo e de visitas de estudo $(n=170)$. Numa posição intermédia do número de referências a práticas selecionadas pelos alunos situam-se a explicação dialogada dos conteúdos com os alunos $(n=118)$ e a exposição/explicação dos conteúdos seguida de exercícios para aplicação/ consolidação dos conhecimentos $(n=110)$, que correspondem também às práticas referidas como muito utilizadas nas três disciplinas.

De acordo com os dados obtidos, os modos de trabalho pedagógico menos apreciados pelos alunos são a realização de atividades de análise de textos e/ou de outros recursos $(n=33)$ e a análise de casos relativos a situações diversas que 
contribuam para o desenvolvimento de competências de pensamento crítico e para a resolução de problemas $(n=38)$.

Por fim, confrontados com o mesmo conjunto de itens, foi pedido aos estudantes para indicarem as práticas curriculares que consideram que proporcionam mais e melhores aprendizagens. Das respostas obtidas, destaca-se a exposição/explicação dos conteúdos seguida de exercícios para aplicação/consolidação dos conhecimentos ( $n=169)$ (que, embora não se trate de uma categoria apontada como mais apreciada, é referenciada com uma das mais eficazes), seguindo-se a prática mais valorizada pelos alunos, ou seja, a realização de trabalhos de grupo $(n=168)$. É também muito referida a exposição/explicação dialogada dos conteúdos com os alunos ( $n=156)$ e a exposição/explicação dos conteúdos $(n=154)$, bem como a realização de trabalhos de campo e de visitas de estudo $(n=121)$. A apresentação de dados ou exemplos para análise pelos alunos seguida de apresentação e explicação dos conceitos em estudo é igualmente valorizada pelos alunos como prática favorecedora da aprendizagem $(n=105)$.

As práticas identificadas como sendo menos eficazes no processo de ensinoaprendizagem correspondem à análise de casos relativos a situações diversas que contribuam para o desenvolvimento de competências de pensamento crítico e para a resolução de problemas $(n=32)$ e a realização de atividades de análise de textos e/ ou de outros recursos $(n=44)$.

Tabela 2: Práticas curriculares docentes mais apreciadas pelos estudantes e que favorecem mais e melhores aprendizagens - perspectiva dos estudantes

\begin{tabular}{|c|c|c|c|c|}
\hline \multirow[t]{2}{*}{$\begin{array}{l}\text { Práticas curriculares docentes } \\
\text { (ensino-aprendizagem) }\end{array}$} & \multicolumn{2}{|c|}{$\begin{array}{l}\text { Práticas mais } \\
\text { apreciadas pelos } \\
\text { estudantes }\end{array}$} & \multicolumn{2}{|c|}{$\begin{array}{l}\text { Práticas favorecedo- } \\
\text { ras de mais e melho- } \\
\text { res aprendizagens }\end{array}$} \\
\hline & $n^{0}$ & Média & $\mathrm{n}^{0}$ & Média \\
\hline Exposição/Explicação dos conteúdos & 99 & 3,3 & 154 & 2,6 \\
\hline $\begin{array}{l}\text { Exposição/Explicação dialogada dos } \\
\text { conteúdos com os alunos }\end{array}$ & 118 & 3,5 & 156 & 2,5 \\
\hline $\begin{array}{l}\text { Exposição/Explicação dos conteúdos } \\
\text { seguida de exercícios para aplicação/ } \\
\text { consolidação dos conhecimentos }\end{array}$ & 110 & 3,3 & 169 & 3,0 \\
\hline $\begin{array}{l}\text { Apresentação de dados ou exemplos } \\
\text { para análise pelos alunos seguida de } \\
\text { apresentação e explicação dos con- } \\
\text { ceitos em estudo }\end{array}$ & 80 & 4,6 & 105 & 3,8 \\
\hline
\end{tabular}




\begin{tabular}{|c|c|c|c|c|}
\hline \multirow[t]{2}{*}{$\begin{array}{l}\text { Práticas curriculares docentes } \\
\text { (ensino-aprendizagem) }\end{array}$} & \multicolumn{2}{|c|}{\begin{tabular}{|c|} 
Práticas mais \\
apreciadas pelos \\
estudantes
\end{tabular}} & \multicolumn{2}{|c|}{$\begin{array}{l}\text { Práticas favorecedo- } \\
\text { ras de mais e melho- } \\
\text { res aprendizagens }\end{array}$} \\
\hline & $n^{0}$ & Média & $n^{0}$ & Média \\
\hline $\begin{array}{l}\text { Realização de atividades que têm em } \\
\text { conta as caraterísticas da turma (co- } \\
\text { nhecimentos prévios; experiências de } \\
\text { vida...) }\end{array}$ & 98 & 5,1 & 82 & 5,1 \\
\hline $\begin{array}{l}\text { Abordagem aos conteúdos seguindo, } \\
\text { predominantemente, a estrutura dos } \\
\text { manuais }\end{array}$ & 71 & 4,8 & 107 & 5,8 \\
\hline $\begin{array}{l}\text { Realização de atividades de pesquisa } \\
\text { bibliográfica ou de pesquisa através } \\
\text { de trabalho de campo }\end{array}$ & 101 & 4,9 & 55 & 5,4 \\
\hline $\begin{array}{l}\text { Realização de trabalhos de campo e } \\
\text { de visitas de estudo }\end{array}$ & 170 & 3,1 & 121 & 3,5 \\
\hline $\begin{array}{l}\text { Recurso a atividades que permitam } \\
\text { transformar as experiências reais dos } \\
\text { alunos em assuntos de aprendizagem }\end{array}$ & 72 & 4,7 & 60 & 4,7 \\
\hline Realização de trabalho de grupo & 199 & 2,9 & 168 & 3,1 \\
\hline $\begin{array}{l}\text { Realização de atividades de análise } \\
\text { de textos e/ou de outros recursos }\end{array}$ & 33 & 6,7 & 44 & 6,5 \\
\hline $\begin{array}{l}\text { Promoção de situações de diálogo e } \\
\text { de partilha de saberes entre os alunos }\end{array}$ & 81 & 5,4 & 84 & 5,4 \\
\hline $\begin{array}{l}\text { Promoção de debates através de fó- } \\
\text { runs virtuais }\end{array}$ & 77 & 4,7 & 53 & 5,4 \\
\hline $\begin{array}{l}\text { Promoção de dinâmicas de debate e } \\
\text { confronto de opiniões numa lógica } \\
\text { argumentativa entre os alunos }\end{array}$ & 49 & 4,7 & 64 & 5,9 \\
\hline $\begin{array}{l}\text { Realização de atividades de análise e } \\
\text { reflexão de situações do dia-a-dia e } \\
\text { do mundo }\end{array}$ & 62 & 6,1 & 62 & 6,6 \\
\hline $\begin{array}{l}\text { Promoção de situações de entreaju- } \\
\text { da entre alunos }\end{array}$ & 78 & 6,3 & 49 & 6,4 \\
\hline $\begin{array}{l}\text { Conceção e desenvolvimento de tra- } \\
\text { balhos de projeto }\end{array}$ & 71 & 6,6 & 55 & 6,9 \\
\hline $\begin{array}{l}\text { Participação em iniciativas de caráter } \\
\text { científico, nomeadamente trabalho } \\
\text { experimental e projetos de investiga- } \\
\text { ção }\end{array}$ & 82 & 5,4 & 84 & 6,1 \\
\hline
\end{tabular}




\begin{tabular}{|c|c|c|c|c|}
\hline \multirow[t]{2}{*}{$\begin{array}{l}\text { Práticas curriculares docentes } \\
\text { (ensino-aprendizagem) }\end{array}$} & \multicolumn{2}{|c|}{\begin{tabular}{|c|} 
Práticas mais \\
apreciadas pelos \\
estudantes
\end{tabular}} & \multicolumn{2}{|c|}{$\begin{array}{l}\text { Práticas favorecedo- } \\
\text { ras de mais e melho- } \\
\text { res aprendizagens }\end{array}$} \\
\hline & $n^{0}$ & Média & $n^{0}$ & Média \\
\hline $\begin{array}{l}\text { Análise de casos relativos a situações } \\
\text { diversas que contribuam para o de- } \\
\text { senvolvimento de competências de } \\
\text { pensamento crítico e para a resolu- } \\
\text { ção de problemas }\end{array}$ & 38 & 6,8 & 32 & 6,8 \\
\hline $\begin{array}{l}\text { Realização de atividades de sistema- } \\
\text { tização e de relação de conhecimen- } \\
\text { tos (gráficos, esquemas, diagramas, } \\
\text { mapas concetuais, ...) }\end{array}$ & 69 & 6,3 & 93 & 6,9 \\
\hline $\begin{array}{l}\text { Realização de atividades promotoras } \\
\text { de criatividade (criar uma nova visão, } \\
\text { uma nova solução, um novo cenário, } \\
\text { planear, imaginar, construir) }\end{array}$ & 71 & 6,8 & 50 & 6,5 \\
\hline Outra (s) & 32 & 5,6 & 32 & 5,5 \\
\hline
\end{tabular}

Fonte: Dados resultantes do estudo

\section{A perspectiva dos professores sobre as práticas curriculares docentes}

Dos 14 professores que participaram do estudo, a maioria é do sexo masculino, mais concretamente $64 \%(n=9)$, sendo os restantes $35,7 \%(n=5)$ do sexo feminino. Metade dos participantes lecionam a disciplina de matemática $(50 \% ; n=7)$, seguindose os professores de físico-química $(28,6 \%$; $n=4)$ e os professores de ciências naturais $(21,4 \% ; n=3)$. Relativamente à experiência profissional na docência, constata-se que a maioria dos professores leciona há mais de 20 anos: 57,1\% $(n=8)$ situam-se na categoria entre 20 e 30 anos e $28,6 \%(n=4)$ exercem a profissão há mais de 30 anos. Além destes, 14,3\% ( $n=2)$ apresentam entre 10 e 19 anos de experiência como professor.

Como é possível verificar na Tabela 3, quando solicitados a responder sobre as práticas curriculares docentes utilizadas com mais frequência e durante mais tempo, os professores referem, predominantemente, a exposição/explicação dos conteúdos seguida de exercícios para aplicação/consolidação dos conhecimentos $(n=10)$ e a exposição/explicação dialogada dos conteúdos com os alunos $(n=9)$. Destacam-se igualmente: a realização de atividades de sistematização e de relação de conhecimentos (gráficos, esquemas, diagramas, mapas conceituais etc.) ( $n=10)$; a realização de atividades de análise e reflexão de situações do dia a dia e do mundo $(n=8)$; a promoção de situações de entreajuda entre alunos $(n=8)$; a realização de atividades que têm em conta as caraterísticas da turma (conhecimentos prévios; 
experiências de vida) ( $n=8)$; e a análise de casos relativos a situações diversas que contribuam para o desenvolvimento de competências de pensamento crítico e para a resolução de problemas $(n=8)$. É ainda de registrar que o equivalente a $50 \%$ dos professores utilizam também a apresentação de dados ou exemplos para análise pelos alunos seguida de apresentação e explicação dos conceitos em estudo $(n=7)$, bem como a realização de trabalhos de grupo $(n=7)$ e a promoção de situações de diálogo e de partilha de saberes entre os alunos $(n=7)$.

As práticas menos assinaladas, logo as menos utilizadas, são a promoção de debates através de fóruns virtuais, a realização de atividades promotoras de criatividade (criar uma nova visão, uma nova solução, um novo cenário, planear, imaginar, construir etc.), e a concepção e desenvolvimento de trabalhos de projeto, com apenas uma ou duas referências.

Tabela 3: Práticas curriculares docentes usadas com mais frequência - perspectiva dos professores

\begin{tabular}{|c|c|c|c|c|c|c|}
\hline \multirow[t]{2}{*}{$\begin{array}{l}\text { Práticas curriculares do- } \\
\text { centes } \\
\text { (ensino-aprendizagem) }\end{array}$} & \multicolumn{2}{|c|}{$\begin{array}{c}\text { Práticas mais } \\
\text { usadas }\end{array}$} & \multicolumn{2}{|c|}{$\begin{array}{l}\text { Práticas mais } \\
\text { apreciadas pelos } \\
\text { estudantes }\end{array}$} & \multicolumn{2}{|c|}{$\begin{array}{lr}\text { Práticas favo- } \\
\text { recedoras de } \\
\text { mais e melhores } \\
\text { aprendizagens }\end{array}$} \\
\hline & $n^{0}$ & Média & $n^{\circ}$ & Média & $n^{0}$ & Média \\
\hline $\begin{array}{l}\text { Exposição/Explicação dos } \\
\text { conteúdos }\end{array}$ & 3 & 3,7 & 2 & 5,0 & 2 & 2,0 \\
\hline $\begin{array}{l}\text { Exposição/Explicação dia- } \\
\text { logada dos conteúdos } \\
\text { com os alunos }\end{array}$ & 9 & 1,4 & 6 & 7,3 & 9 & 1,7 \\
\hline $\begin{array}{l}\text { Exposição/Explicação dos } \\
\text { conteúdos seguida de } \\
\text { exercícios para aplicação/ } \\
\text { consolidação dos conhe- } \\
\text { cimentos }\end{array}$ & 10 & 1,7 & 11 & 4,4 & 10 & 2,5 \\
\hline $\begin{array}{l}\text { Apresentação de dados } \\
\text { ou exemplos para análise } \\
\text { pelos alunos seguida de } \\
\text { apresentação e explica- } \\
\text { ção dos conceitos em es- } \\
\text { tudo }\end{array}$ & 7 & 4,9 & 5 & 5,2 & 5 & 3,8 \\
\hline $\begin{array}{l}\text { Realização de atividades } \\
\text { que têm em conta as ca- } \\
\text { raterísticas da turma (co- } \\
\text { nhecimentos prévios; ex- } \\
\text { periências de vida...) }\end{array}$ & 8 & 5,1 & 6 & 3,2 & 9 & 4,9 \\
\hline
\end{tabular}




\begin{tabular}{|c|c|c|c|c|c|c|}
\hline \multirow[t]{2}{*}{$\begin{array}{l}\text { Práticas curriculares do- } \\
\text { centes } \\
\text { (ensino-aprendizagem) }\end{array}$} & \multicolumn{2}{|c|}{$\begin{array}{c}\text { Práticas mais } \\
\text { usadas }\end{array}$} & \multicolumn{2}{|c|}{$\begin{array}{l}\text { Práticas mais } \\
\text { apreciadas pelos } \\
\text { estudantes }\end{array}$} & \multicolumn{2}{|c|}{$\begin{array}{l}\text { Práticas favo- } \\
\text { recedoras de } \\
\text { mais e melhores } \\
\text { aprendizagens }\end{array}$} \\
\hline & $n^{0}$ & Média & $n^{\circ}$ & Média & $n^{\circ}$ & Média \\
\hline $\begin{array}{l}\text { Abordagem aos conteú- } \\
\text { dos seguindo, predomi- } \\
\text { nantemente, a estrutura } \\
\text { dos manuais }\end{array}$ & 6 & 3,8 & 4 & 5,5 & 5 & 6,4 \\
\hline $\begin{array}{l}\text { Realização de atividades } \\
\text { de pesquisa bibliográfica } \\
\text { ou de pesquisa através de } \\
\text { trabalho de campo }\end{array}$ & 6 & 6,5 & 7 & 5,9 & 7 & 7,0 \\
\hline $\begin{array}{l}\text { Realização de trabalhos } \\
\text { de campo e de visitas de } \\
\text { estudo }\end{array}$ & 3 & 8,0 & 8 & 2,9 & 5 & 7,6 \\
\hline $\begin{array}{l}\text { Recurso a atividades que } \\
\text { permitam transformar as } \\
\text { experiências reais dos alu- } \\
\text { nos em assuntos de apren- } \\
\text { dizagem }\end{array}$ & 5 & 8,4 & 6 & 3,5 & 9 & 6,3 \\
\hline $\begin{array}{l}\text { Realização de trabalho de } \\
\text { grupo }\end{array}$ & 7 & 6,0 & 8 & 4,5 & 5 & 5,6 \\
\hline $\begin{array}{l}\text { Realização de atividades } \\
\text { de análise de textos e/ou } \\
\text { de outros recursos }\end{array}$ & 3 & 6,0 & 3 & 7,3 & 2 & 4,0 \\
\hline $\begin{array}{l}\text { Promoção de situações de } \\
\text { diálogo e de partilha de } \\
\text { saberes entre os alunos }\end{array}$ & 7 & 5,7 & 5 & 6,2 & 8 & 5,1 \\
\hline $\begin{array}{l}\text { Promoção de debates } \\
\text { através de fóruns virtuais }\end{array}$ & 1 & 4,0 & 2 & 2,5 & 1 & 2,0 \\
\hline $\begin{array}{l}\text { Promoção de dinâmicas } \\
\text { de debate e confronto de } \\
\text { opiniões numa lógica ar- } \\
\text { gumentativa entre os alu- } \\
\text { nos }\end{array}$ & 4 & 4,8 & 3 & 2,7 & 4 & 6,8 \\
\hline $\begin{array}{l}\text { Realização de atividades } \\
\text { de análise e reflexão de } \\
\text { situações do dia a dia e do } \\
\text { mundo }\end{array}$ & 8 & 4,8 & 4 & 3,5 & 5 & 5,0 \\
\hline $\begin{array}{l}\text { Promoção de situações de } \\
\text { entreajuda entre alunos }\end{array}$ & 8 & 4,8 & 7 & 3,9 & 6 & 5,5 \\
\hline
\end{tabular}




\begin{tabular}{|c|c|c|c|c|c|c|}
\hline \multirow[t]{2}{*}{$\begin{array}{l}\text { Práticas curriculares do- } \\
\text { centes } \\
\text { (ensino-aprendizagem) }\end{array}$} & \multicolumn{2}{|c|}{$\begin{array}{c}\text { Práticas mais } \\
\text { usadas }\end{array}$} & \multicolumn{2}{|c|}{$\begin{array}{l}\text { Práticas mais } \\
\text { apreciadas pelos } \\
\text { estudantes }\end{array}$} & \multicolumn{2}{|c|}{\begin{tabular}{|cr} 
Práticas favo- \\
recedoras de \\
mais e melhores \\
aprendizagens
\end{tabular}} \\
\hline & $n^{0}$ & Média & $n^{0}$ & Média & $n^{0}$ & Média \\
\hline $\begin{array}{l}\text { Concepção e desenvol- } \\
\text { vimento de trabalhos de } \\
\text { projeto }\end{array}$ & 2 & 6,5 & 4 & 5,0 & 2 & 3,0 \\
\hline $\begin{array}{l}\text { Participação em iniciati- } \\
\text { vas de caráter científico, } \\
\text { nomeadamente trabalho } \\
\text { experimental e projetos } \\
\text { de investigação }\end{array}$ & 5 & 5,8 & 6 & 2,8 & 5 & 3,0 \\
\hline $\begin{array}{l}\text { Análise de casos relativos } \\
\text { a situações diversas que } \\
\text { contribuam para o desen- } \\
\text { volvimento de competên- } \\
\text { cias de pensamento críti- } \\
\text { co e para a resolução de } \\
\text { problemas }\end{array}$ & 8 & 6,2 & 5 & 8,8 & 7 & 5,7 \\
\hline $\begin{array}{l}\text { Realização de atividades } \\
\text { de sistematização e de re- } \\
\text { lação de conhecimentos } \\
\text { (gráficos, esquemas, dia- } \\
\text { gramas, mapas concetu- } \\
\text { ais, ...) }\end{array}$ & 10 & 6,1 & 6 & 7,3 & 8 & 5,9 \\
\hline $\begin{array}{l}\text { Realização de atividades } \\
\text { promotoras de criativi- } \\
\text { dade (criar uma nova vi- } \\
\text { são, uma nova solução, } \\
\text { um novo cenário, planear, } \\
\text { imaginar, construir, ...) }\end{array}$ & 1 & 9,0 & 2 & 6,0 & 3 & 6,3 \\
\hline Outra (s) & 1 & 2,0 & 1 & 6,0 & 1 & 2,0 \\
\hline
\end{tabular}

Fonte: Dados resultantes do estudo

No que concerne às práticas curriculares que, do ponto de vista dos professores, os alunos mais apreciam, destacam-se: a exposição/explicação dos conteúdos seguida de exercícios para aplicação/consolidação dos conhecimentos $(n=11)$; a realização de trabalhos de campo e de visitas de estudo $(n=8)$; a realização de trabalho de grupo $(n=8)$; e a promoção de situações de entreajuda entre alunos $(n=7)$. Registram-se também algumas referências $(n=6)$ à participação em iniciativas de caráter científico, nomeadamente trabalho experimental e projetos de investigação, à realização de 
atividades que têm em conta as caraterísticas da turma (conhecimentos prévios; experiências de vida) e a atividades que permitam transformar as experiências reais dos alunos em assuntos de aprendizagem. As práticas que os docentes consideram ser de menor agrado dos alunos (com 2 referências cada) correspondem a: exposição/ explicação dos conteúdos; realização de atividades promotoras de criatividade (criar uma nova visão, uma nova solução, um novo cenário, planear, imaginar, construir); promoção de debates através de fóruns virtuais.

Quanto às práticas curriculares que os professores consideram que proporcionam mais e melhores aprendizagens, constata-se que as práticas mais assinaladas são, novamente: exposição/explicação dos conteúdos seguida de exercícios para aplicação/consolidação dos conhecimentos $(n=10)$; exposição/explicação dialogada dos conteúdos com os alunos $(n=9)$; realização de atividades que têm em conta as caraterísticas da turma (conhecimentos prévios; experiências de vida) ( $n=9)$. Denota-se que as práticas que os docentes consideram ser mais favorecedoras da aprendizagem estão em consonância com as práticas que os professores indicaram utilizar com mais frequência. O recurso a atividades que permitam transformar as experiências reais dos alunos em assuntos de aprendizagem foi assinalado por 9 professores, mas a média indica que é uma opção intermédia $(m=6,3)$, tal como acontece com a promoção de situações de diálogo e de partilha de saberes entre os alunos ( $n=8 ; m=5,1)$ e com a realização de atividades de sistematização e de relação de conhecimentos (gráficos, esquemas, diagramas, mapas conceituais etc.) $(n=8 ; m=5,9)$. Segundo os docentes, as práticas que são menos favorecedoras de aprendizagens, referidas por dois ou três participantes, são: concepção e desenvolvimento de trabalhos de projeto; realização de atividades de análise de textos e/ou de outros recursos; exposição/explicação dos conteúdos; realização de atividades promotoras de criatividade (criar uma nova visão, uma nova solução, um novo cenário, planear, imaginar, construir etc.). A análise dos dados permite-nos verificar também que as práticas curriculares que os docentes consideram proporcionar menos aprendizagens são coincidentes com as práticas menos utilizadas por estes profissionais.

\section{A perspectiva dos professores sobre as práticas de avaliação da aprendizagem}

Como é possivel constatar na Tabela 4, quando confrontados com o bloco de questões relativo a práticas avaliativas (instrumentos/procedimentos de avaliação da aprendizagem), os professores dão maior importância aos testes escritos individuais $(n=13 ; m=1,8)$ e ao trabalho escrito individual $(n=9 ; m=2,8)$, mas destacam-se também as grelhas de registro sobre aspectos observados durante o processo de ensinoaprendizagem) $(n=11 ; m=3,8)$, os trabalhos de grupo $(n=9 ; m=4,32)$, a apresentação oral de trabalho em grupo seguida de debate $(n=8 ; m=4,5)$, bem como exercícios de autocorreção $(n=8 ; m=4,6)$. Também são usados com alguma frequência o trabalho de campo (indicado por 6 professores) e o questionamento oral (indicado por 7 
elementos).

Tabela 4: Práticas de avaliação da aprendizagem (instrumentos/procedimentos) - perspectiva dos professores

\begin{tabular}{|c|c|c|c|c|c|c|}
\hline \multirow[t]{2}{*}{$\begin{array}{l}\text { Práticas de avaliação da } \\
\text { aprendizagem } \\
\text { (Instrumentos/Procedi- } \\
\text { mentos) }\end{array}$} & \multicolumn{2}{|c|}{$\begin{array}{l}\text { Práticas mais } \\
\text { usadas }\end{array}$} & \multicolumn{2}{|c|}{$\begin{array}{l}\text { Práticas mais } \\
\text { apreciadas pelos } \\
\text { estudantes }\end{array}$} & \multicolumn{2}{|c|}{$\begin{array}{l}\text { Práticas promo- } \\
\text { toras de mais } \\
\text { e melhores } \\
\text { aprendizagens }\end{array}$} \\
\hline & $n^{0}$ & Média & $n^{\circ}$ & Média & $n^{0}$ & Média \\
\hline Testes escritos individuais & 13 & 1,8 & 10 & 4,0 & 11 & 2,7 \\
\hline Trabalho escrito individual & 9 & 2,8 & 9 & 4,1 & 9 & 2,8 \\
\hline Trabalho escrito em grupo & 9 & 4,3 & 12 & 2,2 & 7 & 4,4 \\
\hline $\begin{array}{l}\text { Apresentação oral de tra- } \\
\text { balho em grupo seguida } \\
\text { de debate }\end{array}$ & 8 & 4,5 & 10 & 3,7 & 11 & 3,4 \\
\hline Questionamento oral & 7 & 3,4 & 6 & 3,8 & 5 & 2,8 \\
\hline Portfólio & 5 & 3,8 & 3 & 4,7 & 3 & 5,3 \\
\hline $\begin{array}{l}\text { Grelhas de registo sobre } \\
\text { aspectos observados du- } \\
\text { rante o processo de en- } \\
\text { sino-aprendizagem (ade- } \\
\text { são às tarefas propostas, } \\
\text { participação voluntária na } \\
\text { aula; responsabilidade na } \\
\text { realização das atividades, } \\
\text { comportamento, etc.) }\end{array}$ & 11 & 3,8 & 6 & 4,3 & 7 & 4,0 \\
\hline $\begin{array}{l}\text { Exercícios de autocorre- } \\
\text { ção }\end{array}$ & 8 & 4,6 & 6 & 3,8 & 12 & 2,3 \\
\hline $\begin{array}{l}\text { Autoavaliação a partir de } \\
\text { critérios (ex. participação, } \\
\text { dinâmica de grupo, rela- } \\
\text { tório escrito, reflexão) }\end{array}$ & 6 & 5,0 & 5 & 4,2 & 7 & 4,7 \\
\hline Trabalhos de projeto & 3 & 5,3 & 5 & 2,8 & 4 & 2,8 \\
\hline Teste oral & 0 & & 1 & 6,0 & 1 & 3,0 \\
\hline $\begin{array}{l}\text { Trabalho laboratorial/tra- } \\
\text { balho de campo }\end{array}$ & 6 & 3,2 & 9 & 2,3 & 7 & 2,3 \\
\hline Outro & 0 & & 0 & & 0 & \\
\hline
\end{tabular}

Fonte: Dados resultantes do estudo 
Por outro lado, os instrumentos/procedimentos de avaliação menos utilizados são o teste oral (não foi selecionado por qualquer docente) e o trabalho de projeto (indicado por apenas 3 participantes).

Quanto às práticas avaliativas que os professores consideram que os alunos mais apreciam, é de referir os trabalhos escritos de grupo $(n=12 ; m=2,2)$ e os trabalhos laboratoriais/trabalhos de campo $(n=9 ; m=2,3)$, mas também a apresentação oral de trabalho em grupo seguida de debate $(n=10 ; m=3,7)$, os testes escritos individuais $(n=10 ; 4,0)$, e os trabalhos escritos individuais $(n=9 ; m=4,1)$. Por outro lado, os instrumentos/procedimentos de avaliação que os docentes consideram ser menos apreciados pelos alunos são o teste oral e o portfólio.

Por fim, como se observa na Tabela 4, quando solicitados a indicar os instrumentos/ procedimentos de avaliação que consideram que promovem mais e melhores aprendizagens, os docentes destacam os exercícios de autocorreção $(n=12)$, os testes escritos individuais ( $n=11$ ) e a apresentação oral de trabalho em grupo seguida de debate $(n=11)$. Além destes, também são bastante valorizados os trabalhos escritos individuais $(n=9)$. No pólo oposto, como instrumentos/procedimentos avaliativos que os docentes consideram que menos contribuem para a aprendizagem dos alunos, são também referidos o teste oral e o portfólio.

\section{Considerações finais}

No estudo desenvolvido, os estudantes não mencionaram grandes diferenças nas práticas curriculares mais utilizadas nas disciplinas de matemática, ciências naturais e físico-química, sendo possível constatar que, de um modo geral, as práticas predominantes se coadunam com abordagens curriculares mais tradicionais e tecnicistas (Leite, 2002, 2003; Pacheco, 2001), com o foco na exposição e explicação e muito orientadas pela estrutura dos manuais.

Importa também referir que as práticas curriculares mais apreciadas pelos estudantes (realização de trabalhos de grupo e realização de trabalhos de campo e de visitas de estudo) são reconhecidas pelos professores também no mesmo sentido. Não deixa de ser interessante constatar que, embora os alunos considerem o trabalho de grupo como prática de ensino-aprendizagem mais apreciada, por outro lado, reconhecem que a exposição/explicação dos conteúdos seguida de exercícios para aplicação/consolidação dos conhecimentos é favorecedora de mais e melhores aprendizagens. Reconhecendo-se a complementaridade que existe/deve existir entre processos de ensino-aprendizagem e os processos avaliativos, esta situação poderá estar relacionada com os formatos de avaliação mais usados pelos docentes - teste escrito individual e trabalho escrito individual -, mais ajustados a práticas expositivas e de treino para aplicação do aprendido.

Por outro lado, as práticas curriculares que os docentes consideram ser favorecedoras de mais e melhores aprendizagens estão em consonância com as que 
indicaram utilizar com mais frequência. Considerando que estas referências apontam predominantemente para modos de trabalho pedagógico baseados na transmissão de conhecimento, importará criar condições para a familiarização destes profissionais com estratégias formativas assentes numa cultura de aprendizagem ativa, efetiva e significativa (Hargreaves, Earl, Moore \& Manning, 2001; Joyce, Calhoun \& Hopkins, 2009; Leite, Fernandes \& Sousa-Pereira, 2017; Ellis, 2001; Mayer, 2010; Zabalza, 2000).

Reconhecendo-se que no processo de desenvolvimento do currículo é importante que os professores sejam competentes na definição da ação estratégica para ensinar e promover a aprendizagem dos estudantes (Joyce, Calhoun \& Hopkins, 2009; Ellis, 2001), considera-se que é a este nível que se poderá produzir a mudança efetiva para uma cultura da aprendizagem por contraponto a uma cultura apenas focada no ensino.

Face ao exposto, a reflexão sobre os resultados obtidos poderá constituir um ponto de partida importante para a definição de um plano de melhoria ajustado às necessidades e condições internas do contexto educativo na base deste estudo. Para o efeito, importará perspectivar mudanças organizacionais que apoiem alterações sustentadas nas práticas pedagógicas e didáticas e que sejam capazes de promover o envolvimento ativo dos estudantes no processo de aprendizagem, assim como o desenvolvimento do espírito crítico, da autonomia, da capacidade de tomar decisões e de viver numa sociedade plural e em constante mudança.

No entanto, dada a complexidade subjacente à mudança de práticas docentes, a institucionalização de uma cultura de escola orientada para a construção de aprendizagens ativas, efetivas e significativas terá que passar, necessariamente, pelo trabalho colaborativo de modo a torná-lo uma prática comum e favorável também à aprendizagem e ao desenvolvimento profissional dos professores. Impõe-se, portanto, a assunção de uma liderança educacional, por contraponto a uma direção burocrática (Bolívar, 2012), nomeadamente ao nível da organização dos horários, espaços e recursos que permitam, aos docentes, oportunidades para o trabalho conjunto, para a partilha de experiências e para uma aprendizagem interativa com os pares. Mas impõe-se também que aos profissionais da educação seja possibilitada formação pertinente que permita "aproximarem-se" dos alunos, dos seus interesses e motivações, através de práticas de ensino-aprendizagem e de avaliação ajustadas aos desafios que o exercício da profissão coloca neste século XXI.

\section{Referências bibliográficas}

Ainscow, M., Beresford, J., Harris, A., Hopkins, D., \& West, M. (2001). Crear condiciones para la mejora del trabajo en el aula. Madrid: Narcea.

Amorim, M. \& Alves, M. (2015). "Os fatores organizacionais e o (in)sucesso escolar" in 
Machado, J. (coord.) et al., Educação, territórios e desenvolvimento: atas do I seminário internacional, vol. II. Porto: Universidade Católica Portuguesa do Porto. Faculdade de Educação e Psicologia, 567-578.

Bolívar, A. (2012). Melhorar os processos e os resultados educativos. O que nos ensina a investigação. V. N. Gaia: Fundação Manuel Leão.

Campos, B. P. (2002). Políticas de formação de profissionais de ensino em escolas autónomas. Porto: Edições Afrontamento.

Canário, R. (1996). A escola, o local e a construção de redes de inovação. In B. P. Campos (org.). Investigação e inovação para a qualidade das escolas (pp. 59-76). Lisboa: Instituto de Inovação Educacional.

Crozier, M. (1995). La crise de l'intelligence. Essai sur l'impuissance des élites à se reformer.Paris: Intereditions.

Ellis, A. K. (2001). Teaching, learning, and assessment together: the reflective classroom. NY: Eye On Education.

Fullan, M. (1993). Change forces. Probing the dephts of educational reform. London: Falmer Press.

Fullan, M. (1999). Change Forces: The sequel. Philadelphia: Falmer Press.

Fullan, M. (2003). Change Forces with a Vengeance. Philadelphia: Falmer Press.

Fullan, M., \& Hargreaves, A. (2001). Por que é que vale a pena lutar? O trabalho de equipa na escola. Porto: Porto Editora.

Hargreaves, A. (1998). Os Professores em Tempos de Mudança. O Trabalho e a Cultura dos professores na Idade Pós-Moderna. Lisboa: McGraw-Hill.

Hargreaves, A.; Earl, L.; Moore, S.; Manning, S. (2001). Learning to change: teaching beyond subjects and standards. Jossey-Bass Education Series.

Hopkins, D. (2001). School Improvement for Real. London: Routledge Falmer.

Hopkins, D. (2007). Every School a Great School: Realizing the Potential of System

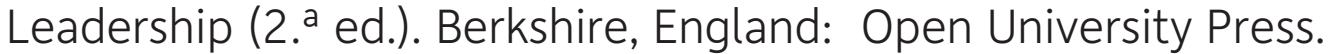

Joyce, B; Calhoun, E. \& Hopkins, D. (2009). Models of learning - Tools for Teaching. England: McGraw-Hill Education. 
Leite, C. (2002). O currículo e o multiculturalismo no sistema educativo português. Lisboa: Fundação Calouste Gulbenkian.

Leite, C. (2003). Para uma escola curricularmente inteligente. Porto: Asa Editores.

Leite, C.; Fernandes, P. \& Sousa-Pereira, F. (2017). "Post-Bologna policies for teacher educaction in Portugal: tensions in building professional identities. Profesorado, Re vista de Currículum y Formación del Profesorado. 21(1), 181-201.

Lima, J. A. (2008). Em busca da boa escola: instituições eficazes e sucesso educativo. Vila Nova de Gaia: Fundação Manuel Leão.

Mayer, R. (2010) Rote Versus Meaningful Learning, Theory Into Practice, 41:4, 226 232.

Moreira, L. (2014). Projeto Fénix: Sentidos de um projeto emergente na construção do sucesso escolar. Porto: Universidade Católica Portuguesa.

Nóvoa, A. (2009). Professores: Imagens do futuro presente. Lisboa: Educa.

Pacheco, J. A. (2001). Currículo: teoria e práxis (2ª ed.). Porto: Porto Editora.

Schön, D. (1992). Formar professores como profissionais reflexivos. In Nóvoa, A. (Ed.). Os professores e a sua formação (pp. 77-91). Lisboa: D. Quixote/IIE.

Thurler, M. (1994). Levar os professores a uma construção activa da mudança. Para uma nova concepção da gestão e da inovação. In M. Thurler \& P. Perrenoud (Orgs.), A escola e a mudança (pp. 33-59). Lisboa: Escolar Editora.

Whitaker, P. (1999). Gerir a mudança nas escolas. Porto: Edições ASA.

Zabalza, M. A. (2000). Enseñando para el cambio. Estrategias didácticas inovadoras. In Sociedad Española de Pedagogía. Ponências Vol. 1, 241-271. XII Congreso Nacional Iberoamericano de Pedagogia. Madrid.

\section{Legislação}

Resolução do Conselho de Ministros n 23/2016 - Programa Nacional de Promoção do Sucesso Escolar 


\section{Biografia}

\section{Ivone Sá}

Agrupamento de Escolas Pintor José de Brito, Viana do Castelo - Portugal

\section{Fátima Sousa-Pereira}

Escola Superior de Educação - Instituto Politécnico de Viana do Castelo; Centro de Investigação e Intervenção Educativas (CIIE) - Faculdade de Psicologia e de Ciências da Educação da Universidade do Porto - Portugal

Email: fatimapereira@ese.ipvc.pt ORCID: https://orcid.org/0000-0002-7533-6372 